\title{
A New Chaotic System with a Pear-Shaped Equilibrium and Its Circuit Simulation
}

\author{
Aceng Sambas ${ }^{1}$, Sundarapandian Vaidyanathan ${ }^{2}$, Mustafa Mamat ${ }^{3}$, \\ Mohamad Afendee Mohamed ${ }^{4}$, WS Mada Sanjaya ${ }^{5}$ \\ ${ }^{1}$ Department of Mechanical Engineering, Universitas Muhammadiyah Tasikmalaya, Indonesia \\ ${ }^{2}$ Research and Development Centre, Vel Tech University, Chennai, India \\ ${ }^{3,4}$ Faculty of Informatics and Computing, Universiti Sultan Zainal Abidin, Malaysia \\ ${ }^{5}$ Department of Physics, Universitas Islam Negeri Sunan Gunung Djati Bandung, Indonesia
}

\begin{tabular}{|c|c|}
\hline Article Info & ABSTRACT \\
\hline Article history: & \multirow{5}{*}{$\begin{array}{l}\text { This paper reports the finding a new chaotic system with a pear-shaped } \\
\text { equilibrium curve and makes a valuable addition to existing chaotic systems } \\
\text { with infinite equilibrium points in the literature. The new chaotic system has } \\
\text { a total of five nonlinearities. Lyapunov exponents of the new chaotic system } \\
\text { are studied for verifying chaos properties and phase portraits of the new } \\
\text { system are unveiled. An electronic circuit simulation of the new chaotic } \\
\text { system with pear-shaped equilibrium curve is shown using Multisim to check } \\
\text { the model feasibility }\end{array}$} \\
\hline Received Jan 11, 2018 & \\
\hline Revised Jul 8, 2018 & \\
\hline Accepted Jul 24, 2018 & \\
\hline$y w o$ & \\
\hline
\end{tabular}

Chaos

Chaotic System

Circuit Design

Dynamical Systems

Equilibrium Points

Copyright $(2018$ Institute of Advanced Engineering and Science. All rights reserved.

\section{Corresponding Author:}

Aceng Sambas,

Department of Mechanical Engineering,

Universitas Muhammadiyah Tasikmalaya, Indonesia.

E-mail: acengs@umtas.ac.id

\section{INTRODUCTION}

In chaos theory, the key important topics are modeling and applications of nonlinear dynamical systems exhibiting chaotic dynamical behavior. Chaotic systems have generated good interest via various science and engineering applications [1]-[7]. Chaos theory has been also applied for special applications such as voice encryption [8], image encryption [9], robotics [10], secure communication [11]-[13] etc.

Many scientists have studied the modelling of chaotic systems having special types of equilibrium curves such as line equilibrium [14, 15], circle [16], hyperbola [17], parabola [18], cloud-shaped curve [19], rectangle [20], ellipse [20], square [21], hyperbolic sine curve [22], hyperbolic tangent curve [23], exponential curve [24], heart-shaped curve [25], conic-shaped curve [26], axe-shaped curve [27], conchshaped curve [28] etc.

In this work, we derive a new chaotic system with a pear-shaped equilibrium curve. Our new system exhibits hidden attractors [29]- [30] as it possesses an infinite number of equilibrium points on a pear-shaped curve. This work makes a new valuable addition to the chaotic systems with closed curves of equilibrium points. We also unveil an electronic circuit simulation of the new chaotic system with a pear-shaped curve of equilibrium points. It is known that checking the feasibility of a chaotic system with electronic circuit realization has practical applications [31]-[35]. 


\section{A NEW CHAOTIC SYSTEM WITH A PEAR-SHAPED EQUILIBRIUM CURVE}

Motivated by the method and structure proposed in [26], we report a new three-dimensional dynamical system given by

$$
\left.\begin{array}{l}
\dot{x}=z \\
\dot{y}=z(-a y-b x z) \\
\dot{z}=c y^{2}-d x^{3}+x^{4}
\end{array}\right\}
$$

Which has a total of five nonlinearities in the dynamics. We show that the system (1) is chaotic for the parameter values $(a, b, c, d)=(15,0.02,6,6)$.

For numerical simulations of phase portraits and for the calculation of Lyapunov chaos exponents, we take the initial values as $X(0)=(0.2,0.2,0.2)$ and parameter set as $(a, b, c, d)=(15,0.02,6,6)$.

The Lyapunov chaos exponents are determined as $\left(L_{1}, L_{2}, L_{3}\right)=(0.0073,0,-0.0084)$. Since $L_{1}>0$, the new system (1) is chaotic. By adding $L_{1}, L_{2}$ and $L_{3}$, we get the sum as -0.0011 , which is negative. This shows that the new system (1) is dissipative. The Kaplan-Yorke dimension is determined as

$$
D_{K Y}=2+\frac{L_{1}+L_{2}}{\left|L_{3}\right|}=2.8690
$$

which is a high value showing the complexity of the new system.

The equilibrium points of the new system (1) are tracked by solving the following system:

$$
\left.\begin{array}{l}
0=z \\
0=z(-a y-b x z) \\
0=c y^{2}-d x^{3}+x^{4}
\end{array}\right\}
$$
equations

Simplifying (3), we see that the equilibrium points of the system (1) are characterized by the two

$$
z=0 \text { and } c y^{2}=x^{3}(x-d)
$$

which is a pear-shaped curve in the $(x, y)$ plane as shown in Figure 1.

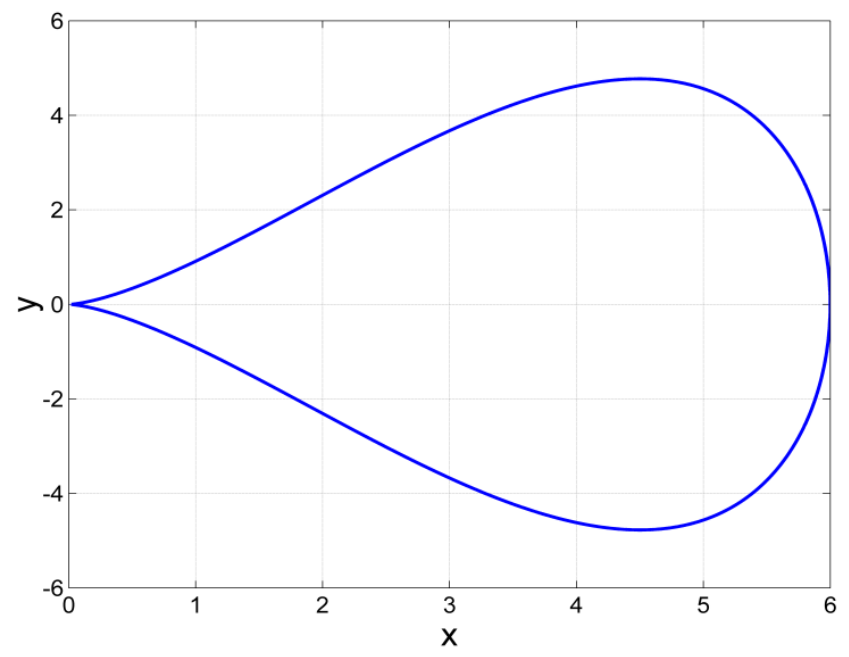

Figure 1. Pear-shaped curve of equilibrium points of the new system (1) 
The phase portraits of the new chaotic system (1) with pear-shaped equilibrium curve are displayed in Figure 2. The Lyapunov chaos exponents of the new chaotic system (1) are displayed in Figure 2 (d).

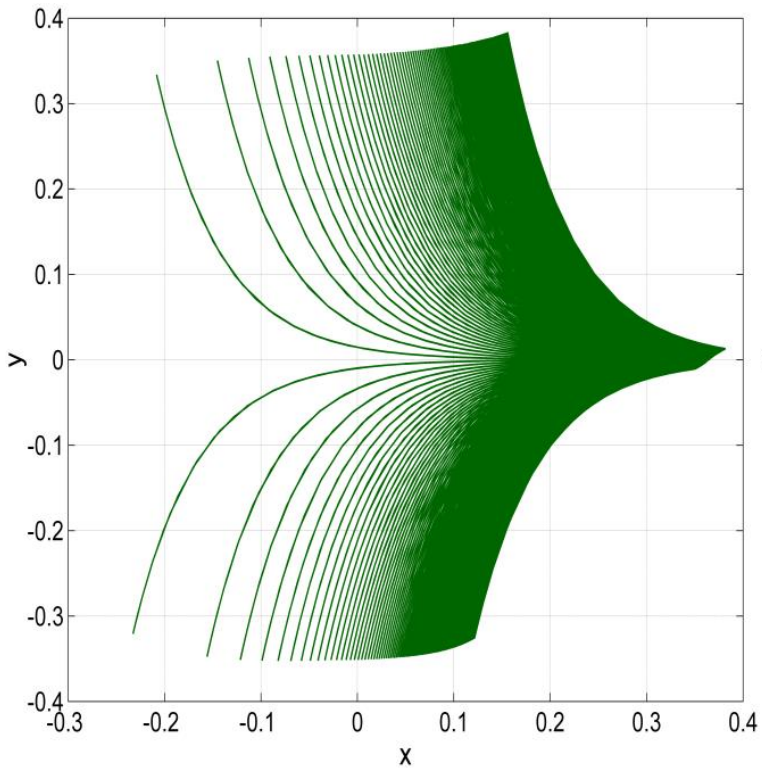

(a)

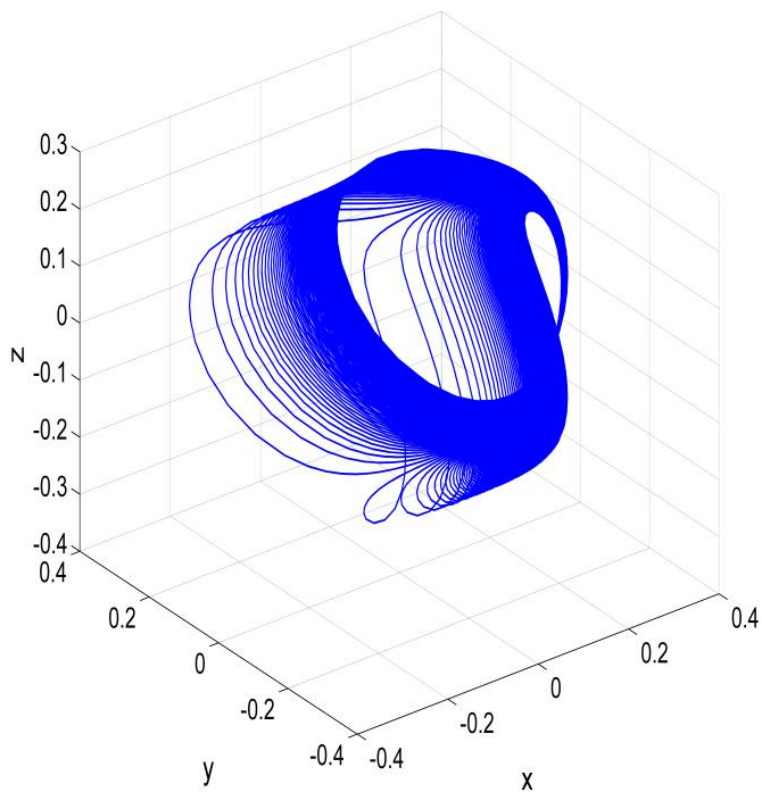

(c)

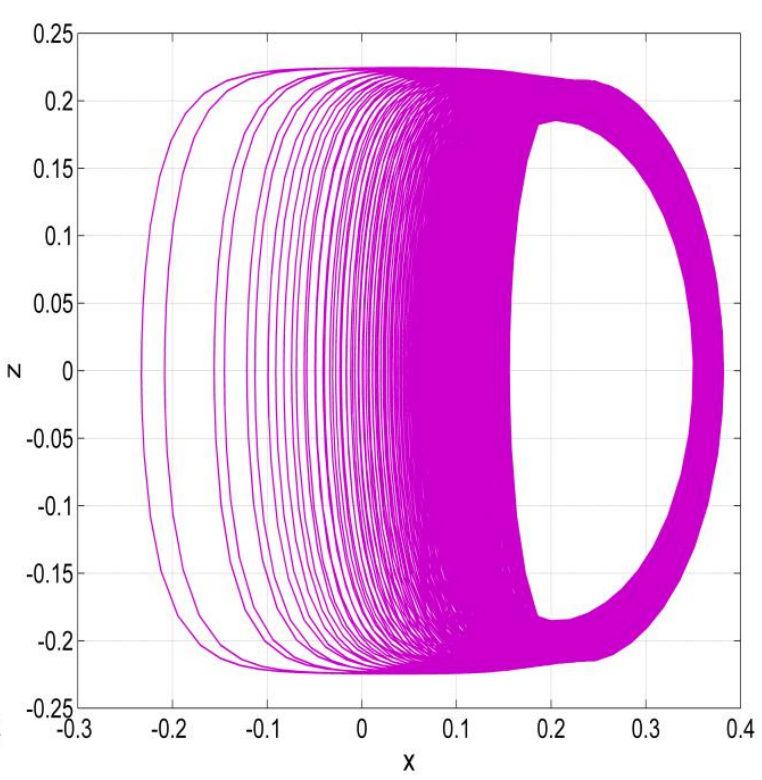

(b)

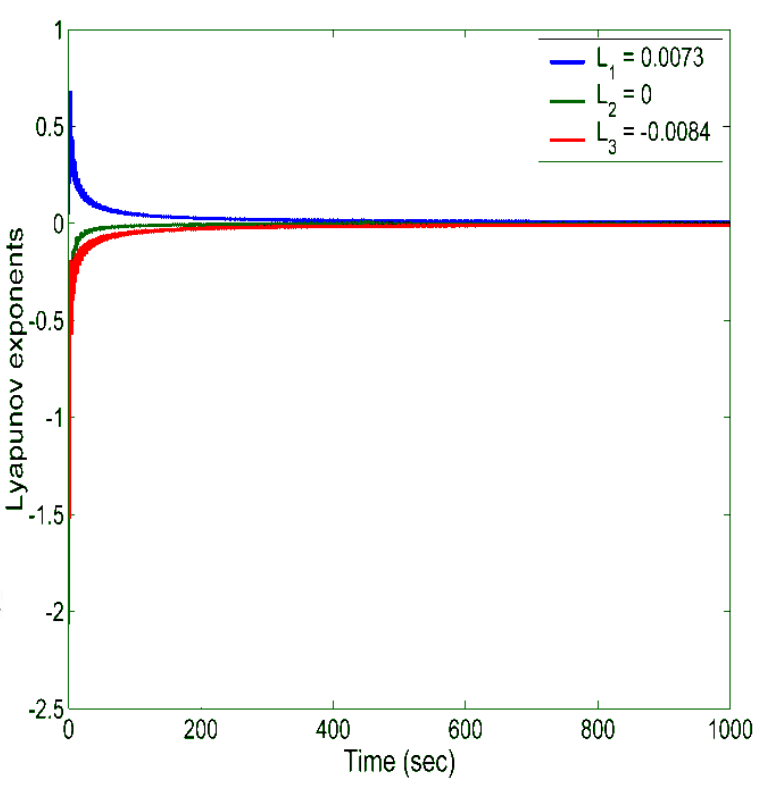

(d)

Figure 2. Numerical simulations of phase portraits of the new chaotic system (1) for $X(0)=(0.2,0.2,0.2)$ and $(a, b, c, d)=(15,0.02,6,6):$ (a) $x-y$ plane, (b) $x-z$ plane, (c) $R^{3}$ and (d) Lyapunov exponents

\section{CIRCUIT IMPLEMENTATION OF THE NEW CHAOTIC SYSTEM}

In order to prove the chaotic behaviors of system (1), a simulation circuit is constructed in this study, which is shown in Figure 3. The new chaotic system (1) can be implemented by the resistance, capacitance, operational amplifier and analog multiplier. Here the variables $x, y, z$ of new chaotic system (1) are the voltages across the capacitor $C_{1}, C_{2}$ and $C_{3}$, respectively.

In this section, three state variables of new chaotic system (1) $\mathrm{x} ; \mathrm{y} ; \mathrm{z}$ are rescaled with amplitude control methods. Therefore the system will be changed int to: 


$$
\left.\begin{array}{l}
\dot{x}=z \\
\dot{y}=z\left(\frac{-a y}{2}-\frac{b x z}{4}\right) \\
\dot{z}=\frac{c y^{2}}{2}-\frac{d x^{3}}{4}+\frac{x^{4}}{8}
\end{array}\right\}
$$

To determine the dynamical equations of the circuit, we apply Kirchhoff's circuit laws into the circuit in Figure 3 so that we have the following circuital equations:

$$
\left.\begin{array}{l}
\dot{x}=\frac{1}{C_{1} R_{1}} z \\
\dot{y}=-\frac{1}{C_{2} R_{2}} y z-\frac{1}{C_{2} R_{3}} x z^{2} \\
\dot{z}=\frac{1}{C_{3} R_{4}} y^{2}-\frac{1}{C_{3} R_{5}} x^{3}+\frac{1}{C_{3} R_{6}} x^{4}
\end{array}\right\}
$$

In (6), $x, y, z$ are the voltages on capacitors $\left(C_{1}, C_{2}, C_{3}\right)$, respectively. We choose $R_{1}=400 \mathrm{k} \Omega, R_{2}=$ $53.33 \mathrm{k} \Omega, R_{3}=80 \mathrm{M} \Omega, R_{4}=133.33 \mathrm{k} \Omega, R_{5}=266.67 \mathrm{k} \Omega, R_{6}=3.2 \mathrm{M} \Omega, R_{7}=R_{8}=R_{9}=R_{10}=R_{11}=R_{12}=100$ $\mathrm{k} \Omega, C_{1}=C_{2}=C_{3}=1 \mathrm{nF}$.

The Multisim simulation oscilloscope outputs (phase portraits) of circuitry of the re-scaled new chaotic system, for parameters $(a, b, c, d)=(15,0.02,6,6)$ are seen in Figure 4. A good agreement between the outputs of the theoretical model and chaotic attractors shown in Figures 2 and Figures 4 confirms the feasibility of the new chaotic system (1).

\section{CONCLUSION}

Discovering chaotic systems with infinite number of equilibrium points such as curve equilibrium is an active topic of research in the chaos literature. In this work, we reported a new chaotic system with a pearshaped equilibrium curve. We also showed an electronic circuit simulation of the new chaotic system to check the feasibility of the chaotic system model.

\section{ACKNOWLEDGEMENTS}

The author Aceng Sambas was supported byPenelitian Dosen pemula (PDP) research Grant No. 0805/K4/KM/2018 from Ministry of Research, Technology and Higher Education of the Republic of Indonesia (KEMENRISTEKDIKTI) 2018. Also, Mustafa Mamat and Mohamad Afendee Mohamed were supported by Government of Malaysia for funding this research under the Fundamental Research Grant Scheme (FRGS/1/2017/ICT03/Unisza/02/2-RR229). 

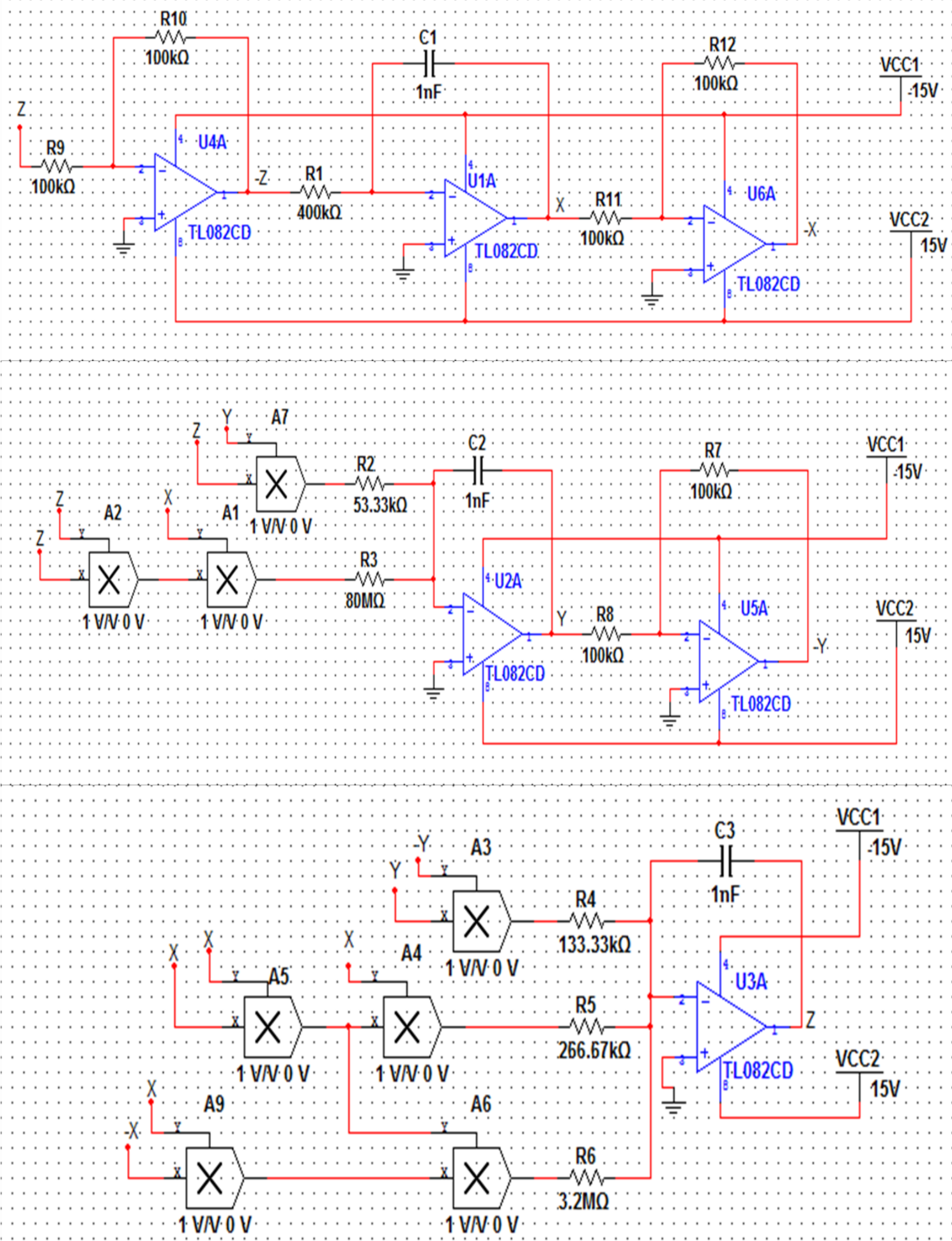

Figure 3. Circuit design of new chaotic system (1) 


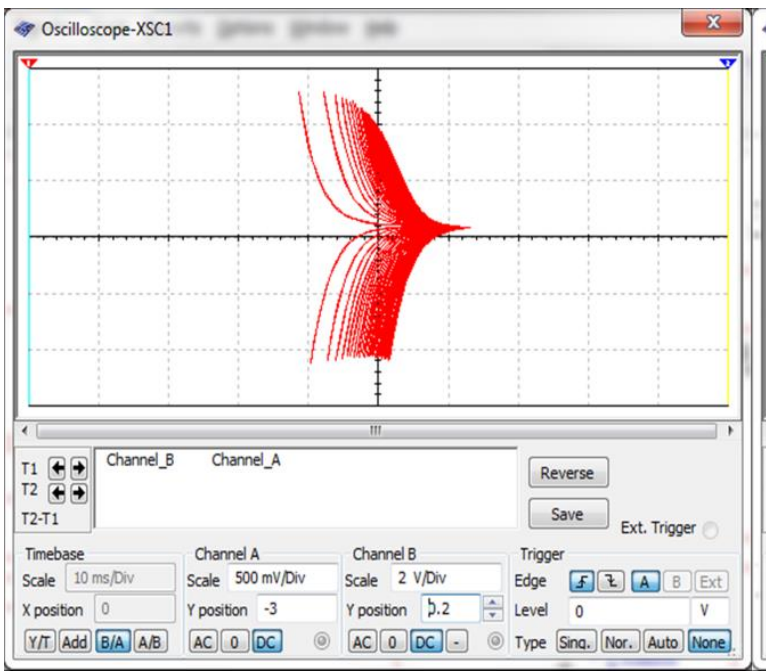

(a)

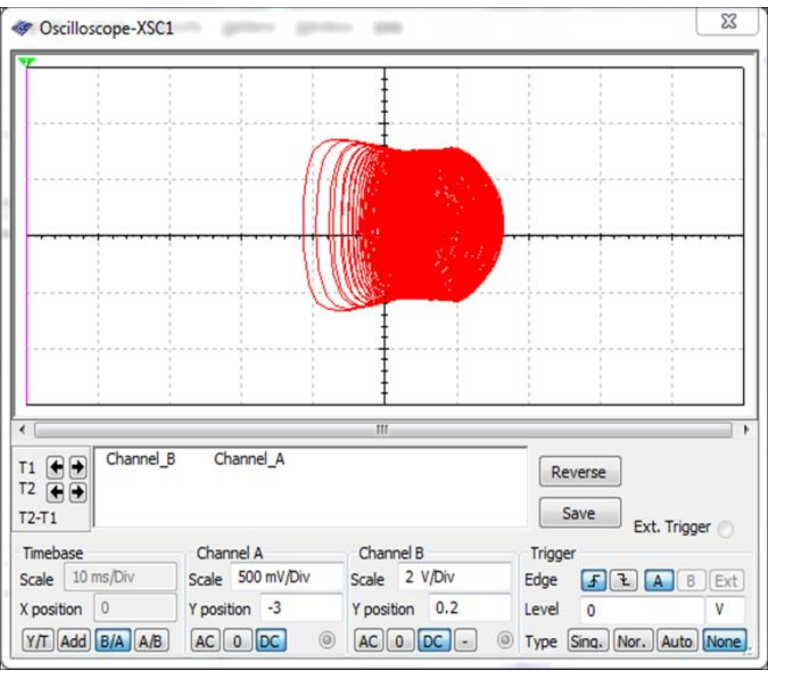

(b)

Figure 4. Chaotic attractors of system (1) using Multisim circuit simulation:

(a) $x$-y plane, and (b) $x-z$ plane

\section{REFERENCES}

[1] S. Rasappan and S. Vaidyanathan, "Global chaos synchronization of WINDMI and Coullet chaotic systems by backstepping control," Far East Journal of Mathematical Sciences, vol. 67, no. 2, pp. 265-287, 2012.

[2] S. Vaidyanathan et al., "Global chaos control of a novel nine-term chaotic system via sliding mode control," Studies in Computational Intelligence, vol. 576, pp. 571-590, 2015.

[3] S. Vaidyanathan, et al., "A new biological snap oscillator: its modelling, analysis, simulations and circuit design." International Journal of Simulation and Process Modelling, vol. 13, no. 5, pp. 419-432, 2018.

[4] S. Vaidyanathan, et al., "A new hyperchaotic temperature fluctuations model, its circuit simulation, FPGA implementation and an application to image encryption." International Journal of Simulation and Process Modelling, vol. 13, no. 3, pp. 281-296, 2018.

[5] S. Vaidyanathan, et al., "A new three-dimensional chaotic system with a cloud-shaped curve of equilibrium points, its circuit implementation and sound encryption." International Journal of Modelling, Identification and Control, vol. 30, no. 3, pp. 184-196, 2018.

[6] R. Zhang, et al., "Bursting oscillations as well as the bifurcation mechanism in a non-smooth chaotic geomagnetic field model." Chinese Physics B, vol. 27, no. 11, art ID 110501, 2018.

[7] F. Nian, et al., "Sliding mode synchronization of fractional-order complex chaotic system with parametric and external disturbances." Chaos, Solitons \& Fractals, vol. 116, pp. 22-28, 2018.

[8] S. Vaidyanathan et al., "Analysis, synchronisation and circuit implementation of a novel jerk chaotic system and its application for voice encryption", International Journal of Modelling, Identification and Control, vol. 28, no. 2, 153-166, 2017.

[9] M. Kaur and V. Kumar. "Efficient image encryption method based on improved Lorenz chaotic system." Electronics Letters, vol. 54, no. 9, pp. 562-564, 2018.

[10] S. Vaidyanathan et al., "A new three-dimensional chaotic system with a hidden attractor, circuit design and application in wireless mobile robot," Archives of Control Sciences, vol. 27, no. 4, pp. 541-554, 2017.

[11] S. Cicek et al., "Secure communication with a chaotic system owning logic element," International Journal of Electronics and Communications, vol. 88, pp. 52-62, 2018.

[12] K. Rajagopal et al., "A Simple Snap Oscillator with Coexisting Attractors, Its Time-Delayed Form, Physical Realization, and Communication Designs," Zeitschrift fr Naturforschung A, vol. 73, no. 5, pp. 385-398, 2018.

[13] A. Sambas et al., "Mathematical Modelling of Chaotic Jerk Circuit and Its Application in Secure Communication System.," Studies in Fuzziness and Soft Computing, vol. 337, pp. 133-153, 2016.

[14] C. Li et al., "Bistability in a hyperchaotic system with a line equilibrium," Journal of Experimental and Theoretical Physics, vol. 118, no. 3, pp. 494-500, 2014.

[15] S. Jafari and J. C. Sprott, "Simple chaotic flows with a line equilibrium," Chaos, Solitons \& Fractals, vol. 57, pp. 79-84, 2013.

[16] T. Gotthans and J. Petrzela, "New classes of chaotic systems with circular equilibrium," Nonlinear Dynamics, vol. 81, no. 3, pp. 1143-1149, 2015.

[17] S. Kingni, et al., "A chaotic system with an infinite number of equilibrium points located on a line and on a hyperbola and its fractional-order form," Chaos, Solitons \& Fractals, vol. 99, no. 1, pp. 209-218, 2017. 
[18] S. Jafari, "Simple chaotic 3D flows with surfaces of equilibria" Nonlinear Dynamics, vol. 86, no. 2, pp. 13491358, 2016.

[19] X. Wang, et al., "Dynamics, circuit design and synchronization of a new chaotic system with closed curve equilibrium," Complexity, vol. 2017, art ID 7138971, 2017.

[20] V. T. Pham, et al., "A chaotic system with different shapes of equilibria," International Journal of Bifurcation and Chaos, vol. 206, art ID 1650069, 2016.

[21] T. Gotthans, et al., "Simple chaotic flow with circle and square equilibrium," International Journal of Bifurcation and Chaos, vol. 26, art ID 1650137, 2016.

[22] V. T. Pham, et al., "Bistable Hidden Attractors in a Novel Chaotic System with Hyperbolic Sine Equilibrium," Circuits, Systems, and Signal Processing, pp. 1-6, 2017.

[23] V. T. Pham, et al., "Dynamics and circuit of a chaotic system with a curve of equilibrium points," International Journal of Electronics, vol. 105, pp. 385-397, 2018.

[24] E. Tlelo-Cuautle, et al., "Dynamics, FPGA realization and application of a chaotic system with an infinite number of equilibrium points," Nonlinear Dynamics, vol. 89, pp. 1129-1139, 2017.

[25] V. T. Pham, et al., "A novel chaotic system with heart-shaped equilibrium and its circuital implementation," Optik, vol. 131, pp. 343-349, 2017.

[26] J. Petrzela, et al., "New Chaotic Dynamical System with a Conic-Shaped Equilibrium Located on the Plane Structure," Applied Sciences, vol. 7, pp. 976-988, 2017.

[27] S. Vaidyanathan, et al., "A new chaotic system with axe-shaped equilibrium, its circuit implementation and adaptive synchronization." Archives of Control Sciences, vol. 28, no. 3, pp. 443-462, 2018.

[28] M. Mamat et. al., "A new 3-D chaotic system with conch-shaped equilibrium curve and its circuit implementation." International Journal of Engineering \& Technology, vol. 7, no. 3, pp. 1410-1414

[29] G. Leonov et al., "Hidden oscillations in dynamical systems," Transaction on Systems and Control, vol. 6, pp. 5467, 2011.

[30] G. Leonov et al., "Hidden attractor and homoclinic orbit in Lorenz-like system describing convective fluid motion in rotating cavity," Communications in Nonlinear Science and Numerical Simulation, vol. 28, pp. 166-174, 2015.

[31] A. Sambas et al., "Numerical Simulation and Circuit Implementation for a Sprott Chaotic System with One Hyperbolic Sinusoidal Nonlinearity," Far East Journal of Mathematical Sciences, vol. 102, no. 6, 1165-1177, 2017.

[32] A. Sambas et. al., "A new 4-D chaotic system with hidden attractor and its circuit implementation." International Journal of Engineering \& Technology, vol. 7, no. 3, pp. 1245-1250, 2018.

[33] C. Li, et. al., "Absolute term introduced to rebuild the chaotic attractor with constant Lyapunov exponent spectrum.” Nonlinear Dynamics, vol. 68, no. 4, pp. 575-587, 2012.

[34] C. Zhu, et. al., "Cryptanalysis and Improvement on an Image Encryption Algorithm Design Using a Novel Chaos Based S-Box." Symmetry, vol. 10, no. 9, art ID 399, 2018.

[35] M. Yu, et. al., "A hyperchaotic map with grid sinusoidal cavity." Chaos, Solitons \& Fractals, vol. 106, pp. 107$117,2018$.

\section{BIBLIOGRAPHIES OF AUTHORS}

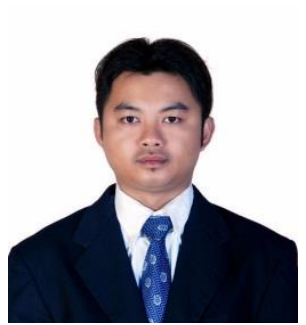

Aceng Sambas is currently a Lecturer at the Muhammadiyah University of Tasikmalaya, Indonesia since 2015. He received his M.Sc in Mathematics from the Universiti Sultan Zainal Abidin (UniSZA), Malaysia in 2015. His current research focuses on dynamical systems, chaotic signals, electrical engineering, computational science, signal processing, robotics, embedded systems and artificial intelligence

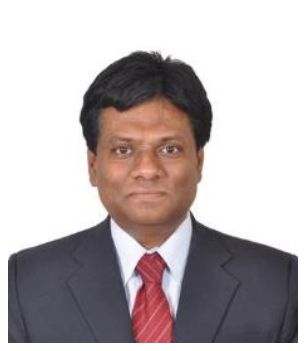

Sundarapandian Vaidyanathan is a Professor at the Research and Development Centre, Vel Tech University, Chennai, India. He earned his D.Sc. in Electrical and Systems Engineering from the Washington University, St. Louis, USA in 1996. His current research focuses on control systems, chaotic and hyperchaotic systems, backstepping control, sliding mode control, intelligent control, computational science and robotics. He has published three text-books on mathematics and twelve research books on control engineering. He has published over 410 Scopus-indexed research publications. He has also conducted many workshops on control systems and chaos theory using MATLAB and SCILAB. 


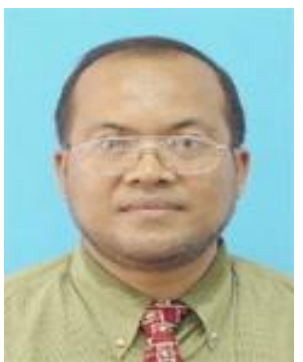

Mustafa Mamat is currently a Professor and the Dean of Graduate School at Universiti Sultan Zainal Abidin (UniSZA), Malaysia since 2013. He was first appointed as a Lecturer at the Universiti Malaysia Terengganu (UMT) in 1999. He obtained his PhD from the UMT in 2007 with specialization in optimization. Later on, he was appointed as a Senior Lecturer in 2008 and then as an Associate Professor in 2010 also at the UMT. To date, he has successfully supervised more than 60 postgraduate students and published more than 150 research papers in various international journals and conferences. His research interests include conjugate gradient methods, steepest descent methods, Broydens family and quasi-Newton methods.

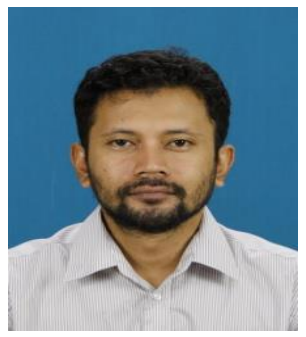

Mohamad Afendee Mohamed received his PhD in Mathematical Cryptography from Universiti Putra Malaysia in 2011 and currently serves as a senior lecturer at Universiti Sultan Zainal Abidin. His research interests include both theoretical and application issues in the domain of information security, and mobile and wireless networking.

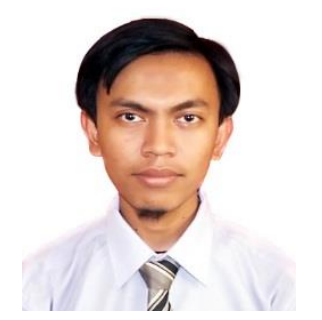

Mada Sanjaya WS received his Ph.D in Mathematics from the University Malaysia Terengganu, Malaysia in 2012. He was first appointed as a Lecturer at the UIN Sunan Gunung Djati Bandung, Indonesia in 2009. His research interests include nonlinear dynamical systems, chaotic systems, artificial intelligence, soft computing and robotic systems. 